\title{
A razão agoniza em uma casa vazia: modernismo arquitetônico no filme O Desafio
}

\section{Carlos Eduardo Pinto}

Professor do Departamento de História do Instituto de Filosofia e Ciências Humanas da UERJ/ Professor Colaborador do Programa de Pós-Graduação em História da UERJ.

Contato: dudachacon@gmail.com

\section{RESUMO}

O filme $O$ desafio, dirigido por Paulo César Saraceni em 1965, é um marco do Cinema Novo brasileiro. Considerada a primeira obra cinematográfica a tratar abertamente do Golpe civil-militar de 1964, também inaugurou uma linhagem de filmes cariocas intimistas, empenhados em realizar leituras que ultrapassassem a representação da cidade por meio de imagens de cartão-postal. A película dedica atençáo especial aos cenários, sobretudo às casas e apartamentos, definindo os contornos políticos e psicológicos dos personagens por meio de sua interação com os ambientes. $\mathrm{O}$ artigo se estrutura sobre a apreensão do impacto causado por essa nova forma de representaçáo urbana e se completa com a análise de duas sequências, em que uma casa modernista quase vazia é contraposta a uma pensão incendiada, em ruínas. Enquanto os contornos dos cenários definem os conflitos dos protagonistas, as açóes desenroladas em cada ambiente agregam sentido à arquitetura.

Palavras-chave: arquitetura modernista, Cinema Novo, $O$ desafio

\section{ABSTRACT}

Paulo César Saraceni's The dare (1965) is a milestone of the Brazilian Cinema Novo. Considered the first cinematographic movie to openly address the 1964 civil-military coup, it also inaugurated a lineage of intimate Rio films, committed to reading beyond the representation of the city through postcard images. The film pays special attention to the scenarios, especially houses and apartments, defining the political and psychological contours of the characters through their interaction with the environments. In this article I make explicit the impact caused by this new form of urban representation and, finally, I make the analysis of two sequences, in which an almost empty modernist house is set against a burning, ruined pension. The aim is to demonstrate that, while the contours of these scenarios define the protagonists' conflicts, the actions taken in each environment add meaning to the architecture.

Key-Words: modernist architecture, New Cinema, The dare 


\section{Introduçáo}

Paulo César Saraceni foi um dos criadores do Cinema Novo brasileiro, dirigindo filmes que, embora comprometidos com os pressupostos políticos que embasavam o movimento, também se dedicavam a perscrutar a intimidade de seus personagens. Em 1965, com verba para filmar um roteiro sobre um caso famoso de infanticídio no Rio de Janeiro, Saraceni decidiu que era mais urgente fazer um filme sobre o impacto do Golpe civil-militar sobre sua geração. Batizado de $O$ desafio, a obra se debruçaria sobre reflexóes em diversas áreas intelectuais e artísticas, de modo a criar um painel sobre possíveis respostas ao fato político. Ainda, inauguraria um novo estilo de representação da realidade urbana carioca, afastando-se da oposição "belezas naturais x exclusão social”. Por meio das situaçôes vivenciadas por seu protagonista, o filme efetua referências ao cinema, ao teatro, à literatura, à música, ao jornalismo, à psicologia, à política, à filosofia e à arquitetura - que, junto com a representação urbana, é o foco desse artigo.

A diegese do filme é formada, basicamente, pelos conflitos de um jovem jornalista, Marcelo (Oduvaldo Viana Filho, o Vianinha), diante do Golpe civil-militar de 1964. Intrínseca a suas reflexões sobre a atuação da esquerda, sobretudo no campo da criação artística, ocorre a crise de seu romance com Ada (Isabella), esposa de um industrial. O roteiro, também de Saraceni, recorre a falas que tratam explicitamente do contexto posterior ao Golpe. As atuaçóes beiram o estilo brechtiano, quase prescindindo da mediação do "faz-de-conta" ilusionista do naturalismo, mantendo-se no limiar entre esses dois modos de narrar. A condu- ção da câmera, realizada por Dib Lutfi ${ }^{1}$, dirigido por Guido Consulich, deve muito ao estilo documental, principalmente no que se refere ao Cinema Verdade, que Saraceni havia experimentado no curta Integração Racial (1964). Tantas novidades não passariam em branco, atraindo uma recepção polêmica para a obra, como apresento a seguir.

\section{Reaçóes}

Rodado em 14 dias, devido a um orçamento apertado, $O$ desafio foi apresentado em 1965 no Festival Internacional do Filme (FIF), no Rio, gerando debates acalorados entre a crítica e o público. Tais reaçôes são representativas da década de 1960, quando o cinema brasileiro estava inserido nas "tramas da cultura", nos termos de Tales Ab’Sáber (2003, p.23). Já que tal afirmação poderia ser estendida a qualquer produto social, em qualquer época, acredito que aqui ela se refira à intensidade com que os filmes eram recebidos naquele momento. Afinal, as discussóes ultrapassavam a esfera estritamente cinematográfica, atingindo também outras áreas, como a sociologia, a antropologia e, sobretudo, a política.

Após sua estreia no Festival, o filme foi detido pelo governo, que o prendeu por oito meses, sem qualquer pronunciamento, sempre se referindo à liberaçáo como algo que seria resolvido em breve (CAMPO, 2011). Num momento em que a ditadura civil-militar tateava, procurando delinear os contornos de sua atuação ainda "envergonhada" (GASPARI, 2002), a censura não fazia parte sistemática do amplo repertório de açôes coercivas de que o regime lançava mão, embora documentos da Polícia Política do Rio de Janeiro 
apresentem alguns indícios de que a Censura Nacional já fosse vista como uma necessidade "na luta contra o comunismo"(CENTRO DE INFORMAÇÓES, 1966) $)^{2}$. Finalmente, em maio 1966, O desafio estreou, tendo sofrido a eliminação de algumas falas na banda sonora (as imagens permaneceram, porém, "mudas").

A Censura havia atiçado a imaginação da crítica e do público, intensificando ainda mais as reaçóes. Mônica Brincalepe Campo (2011) percebeu uma divisão, certamente não estanque, entre os críticos do Rio, avessos à película e de São Paulo, elogiosos. Sua interpretação envolve o Centro Popular de Cultura (CPC) da UNE, cuja força em terras cariocas seria a responsável pela rejeição ao filme. Entre os motivos dos ataques, estava a postura inerte do protagonista diante do contexto pós-64, com a qual o $\mathrm{CPC}$ não concordava.

Além dessa distinção entre paulistanos e cariocas, também percebo diferenças entre os que leram o filme pensando apenas nas açóes de seus personagens e os que também levaram em conta as experimentaçóes estilísticas da obra. A apreensão dos personagens como figuras plausíveis, com as quais seria possível se identificar ou entrar em conflito, permitiu ao filme ser apropriado como discurso político. Não menos politizadas, as avaliaçóes que consideraram seus aspectos estéticos perceberam outras potencialidades, incluindo a inovação no modo como se dava a interpretaçáo do universo urbano. Por exemplo, J. A. Pereira da Silva (1966) entende $O$ desafio como uma sucessáo de quadros aparentemente desconexos, sem enredo, que levariam o espectador a pensar sobre o seu contexto. É justamente como parte desse esforço de levar o espectador a "se ver", que o autor insere a representação urbana como um dado estético relevante, fazendo algumas associações com outros filmes da época:
A favela e o agreste, cujos aspectos foram enfatizados dialeticamente no período inicial, anterior aos acontecimentos de abril de 1964, cedem lugar agora às ruas delineadas, aos edifícios de apartamentos, ao borborinho [sic] metropolitano, por onde caminha um homem limpo, civilizado, empregado e torturado. Foi o que vimos em "São Paulo S. A.", é o que veremos em " $A$ grande cidade" de Carlos Diegues, " $O$ desafio" de Paulo César Saraceni, em " $A$ Terra em transe", que Glauber Rocha está realizando, e outros filmes em produção. As contradiçôes de áreas e classes sociais são substituídas por contradiçóes internas da burguesia, numa fase histórica estagnada (SILVA, 1966) ${ }^{3}$.

Além de evocar o Golpe de 1964 como inflexáo, o crítico Pereira da Silva (1966) aponta ligaçóes com outros filmes, fazendo de $O$ desafio uma obra inaugural. De fato, os filmes elencados - com exceção de A grande cidade, que o crítico citou antes de ver, talvez confiando em demasia no título - estabelecem uma relação diferenciada com o universo urbano. Deixa-se de lado o contexto da exclusão social representado pelas favelas, para enfocar aspectos mais "modernos" da urbe.

Essa apreensão foi confirmada por alguns cineastas, como Glauber Rocha, que destacaria a representação urbana de $O$ desafio, afirmando que "(...) o subdesenvolvimento também está nas cidades, nos bairros grã-finos, nas boutiques de luxo, em Ipanema(...)" (ROCHA, 2004, p. 143). O diretor ainda voltaria a tratar do filme em 1980, referindo-se à sua múltipla importância: 
Pela primeira vez os personagens do cinema brasileiro aparecem discutindo psicologia, economia, política, história, amor, sexo, psicanálise, revolução. Reagiram (elites e povo) contra os diálogos, considerados superficiais. Paulo Francis esclareceu num artigo "Adeus às vacas" a importância desse diálogo - era o deslocamento do ruralismo ao urbanismo com todas as implicações decorrentes - outro espaço, outra montagem, outras ideias logo outros diálogos, outro som, outras interpretaçóes, outro filme, cinema novo.(...) (ROCHA, 2004, p. 437).

Em relação à representação urbana, a perspectiva de Glauber se diferencia da de Rogério Sganzerla. Esse futuro cineasta, que estrearia com $O$ bandido da luz vermelha (1968), elogia uma sequência em que o protagonista caminha por uma feira durante dois minutos, sem nenhum motivo além de estabelecer "uma fantástica reconciliação entre a câmera" e o cenário, que ele chama de "décor" (SGANZERLA, 1966, p. 5). Assim, enquanto Glauber percebe uma transposição da temática do subdesenvolvimento, comumente representada nas favelas e no sertáo, para as áreas mais nobres da cidade, Sganzerla entende a representação urbana apenas como um esforço de inovação estética. Em sua perspectiva, a câmera sustenta situaçóes corriqueiras por mais tempo do que seria necessário, com o simples motivo de filmar o mundo. Pela ótica de Deleuze (2005, p. 8), essa é uma das marcas do cinema moderno, em sua busca por "situaçôes óticas puras [que] descobrem ligaçóes de um novo tipo, que não são mais as sensório-motoras, e póem os sentidos liberados em relaçóes diretas com o tempo, com o pensamento".
Tais percepçôes do filme transparecem a complexidade de seu enredo e de sua narrativa que, como apontado, se dedicavam a sobrepor inúmeras referências artísticas e intelectuais, enquanto buscavam fazer uma representação inovadora da realidade urbana. Embora não tenha o objetivo de abarcar a totalidade dessa empreitada, dedico-me agora a traçar alguns comentários sobre os aspectos do filme que considero mais relevantes para o tema que me propus a tratar.

\section{A cidade intangível}

A diegese de $O$ desafio se desenvolve por meio de cenas que apresentam os protagonistas, Marcelo e Ada, durante encontros amorosos ou, separadamente, em contextos diversos - ele, na redação da revista $O$ Cruzeiro, em que trabalha, no show Opiniāo, num bar com os amigos; ela, em casa ou na fábrica da família, que visita com a pretensão de assumir o romance extraconjugal para o marido.

Em todos as ocasiōes, há mecanismos que buscam reforçar o filme como uma narrativa urbana, com ritmos marcados pelas multidóes, engarrafamentos, ruídos de motores. Contudo, por meio de uma sequência filmada na redação de $O$ Cruzeiro, essa filiação é reforçada. Trata-se de uma conversa entre Marcelo e Carlos, um fotógrafo com quem ele pretende escrever um livro. O diálogo se mostra bastante instigante frente ao tema da representação da cidade, já que o livro abordaria "assunto urbano". Carlos diz que não devem ficar "conversando muito", concluindo que, se "eles querem assunto urbano, nem é preciso sair do Rio". Bastaria "ficar com a chamada classe privilegiada [e] sair por aí batendo as fotos pela Zona Sul". Marcelo retruca que só não começa a trabalhar porque "não está acreditando". A câmera se move pelo espaço entre eles, possibilitando perspectivas diferentes, 
sem haver cortes na montagem. Carlos arremata: "Você acha que eu estou satisfeito com a ideia do livro? Que era isso que eu queria fazer agora? O livro é um caminho. É o que podemos fazer agora”. Depois de um longo debate, em que sua postura inerte é criticada, Marcelo arremata: "Se você descobrir uma solução, uma melhora, parabéns. Mas eu ainda estou vendo tudo escuro".

Aqui, o filme lança mão de um recurso metalinguístico: ele também é uma obra de "assunto urbano", realizada sem que fosse preciso sair do Rio. Portanto, a narrativa se replica na diegese, marcando a diferença em relação aos filmes que haviam ido para o Nordeste ou subiram os morros para representar as favelas. Saraceni fala sobre isso numa entrevista a Alex Viany, contemporânea ao filme, em que lembra uma conversa de botequim que tivera com Nelson Pereira dos Santos. Na ocasião, Nelson the falara sobre a possibilidade de fazer filmes na cidade: "Urbano, lembrava ele, significa também uma pessoa 'cortês, afável, civilizada', bem comportada [sic]. Acho que eles querem esse tipo de cinema. Mas vamos ao cinema urbano: a gente aproveita, faz filme na cidade e manda brasa" (VIANY, 1999, p. 121).

Note-se a utilização do pronome pessoal "eles" para se referir a uma demanda por filmes urbanos, exatamente como na fala de Carlos, quando diz que, se "eles querem assunto urbano, nem é preciso sair do Rio". Em ambas as situaçôes, a construção aponta para um desejo geral, sem sujeito determinado. Quem quer cinema urbano "comportado"? A crítica? O público? Os governantes? Todos, talvez. Pelo paralelo que se estabelece entre o livro que Marcelo pretende escrever e o filme que Saraceni realizou, subentende-se que, para ambos, o papel do artista deveria ser filmar na cidade, mas sem atender a essa demanda.
Assim, em vez de somente filmar a "chamada classe privilegiada" da Zona Sul, representada por Ada, o filme a contrapóe ao amante de classe média baixa, ativista político, deprimido por conta da ditadura e da crise em seu relacionamento. É basicamente a partir desses dois pontos de vista que a cidade é focalizada. Movimento semelhante ocorre com a representação da arquitetura modernista, confirme apresento a seguir.

\section{A casa vazia}

Após sequências em que Marcelo assiste ao espetáculo Opinião, Ada surge na varanda de uma casa, vendo Marcelo chegar da rua. A diegese não localiza a residência na geografia urbana, sem nenhum acidente topográfico ou elemento construído que permita reconhecer em que bairro ela está. Por meio dos diálogos, fica subentendido tratar-se da casa de uma amiga dela que viaja muito e que, por isso, cede o espaço para os amantes. Já no interior, Marcelo anda de mãos dadas com Ada, dizendo que havia se esquecido "daquela vista". A paisagem em questão é mostrada através de um pano de vidro enquadrado do lado esquerdo da tela, permitindo a vista de um paredão rochoso coberto de vegetaçáo, acompanhado de casas tradicionais, com telhados de duas águas.

A casa em que eles estão, ao contrário, é modernista (figs 1 e 2). Além do pano de vidro, a sala apresenta outros elementos típicos do estilo, como descritos por Juliana Weinberg (2005, p. 176, grifos meus): "linhas retas, volumes geométricos regulares, cores neutras, materiais industrializados, funcionalismo $e$ racionalidade". Ainda, os amplos espaços internos são ocupados por móveis que seguem o padrão de mobiliário modernista brasileiro, aliando design retilíneo a materiais naturais, como madeira e couro ${ }^{4}$. 
Segundo Lauro Cavalcanti (2006), o modernismo brasileiro se firmou em três frentes: encomendas estatais (Palácio Capanema; Pampulha; Brasília; Aterro do Flamengo); arquitetura social (unidades habitacionais da Gamboa e do Pedregulho) e preservação (SPHAN/IPHAN, cidades históricas). Era um programa ousado, que procurava ligar passado e futuro, intervindo na sociedade de modo a solucionar as mazelas sociais e educar cidadáos e cidadãs para uma vida coletiva e democrática. O Cinema Novo manteve diálogo com esses três vetores, em filmes como A grande cidade (Cacá Diegues, 1966) e Brasilia, contradiçôes de uma cidade nova (Joaquim Pedro de Andrade, 1967). No entanto, ainda exploraria mais um campo, que é justamente o destacado em $O$ desafio: denunciar, com perspectiva crítica, o modernismo como signo de exclusão social - já que muitos personagens burgueses moram em residências modernistas - , e de racionalismo estéril, no sentido de um excesso de reflexóes que, ao invés de levarem à ação, imobilizam. Aqui, embora não seja desprezível o fato de a casa pertencer a uma amiga de Ada (provavelmente, uma burguesa), é o segundo sentido que parece ter mais interesse para a narrativa.

Ada e Marcelo conversam, mais uma vez, sobre a crise de seu relacionamento. As frases são marcadas por pausas longas, que deixam reverberar o silêncio do ambiente. Os atores mantêm uma postura ereta e se posicionam de frente ou de lado em relação à câmera, mantendo certo espaço entre si. Tais opçóes da mise-en-scène, ao mesmo tempo que mimetiza as linhas retas do cenário, enfatiza a frieza da relação. Ada se refere ao início da história deles e um flashback os apresenta visitando as ruínas de uma "pensão muito conhecida", incendiada por um rapaz que não possuía dinheiro para pagar o seu quarto. Desde o início do flashback, uma música extradiegética executada ao piano dá um tom delicado, emotivo e um pouco nostálgico à sequência 5 . Durante muito tempo, eles caminham entre os escombros, com a câmera os acompanhando, até que Marcelo sugere que procurem o quarto do incendiário (figs. 3 a 4). Nesse momento, a música já não é mais executada. Após um corte, a câmera passeia pelas paredes queimadas do quarto, mostrando os tijolos aparentes. Marcelo chama Ada para que ela veja as folhas soltas que achou, onde estão escritos dois trechos de poemas, que ambos reconhecem como parte do livro Invenção de Orfeu, de Jorge de Lima:

Também há as naus que não chegam mesmo sem ter naufragado: não porque nunca tivessem quem as guiasse no mar ou não tivessem velame ou leme ou âncora ou vento

Fonte: Frames do filme
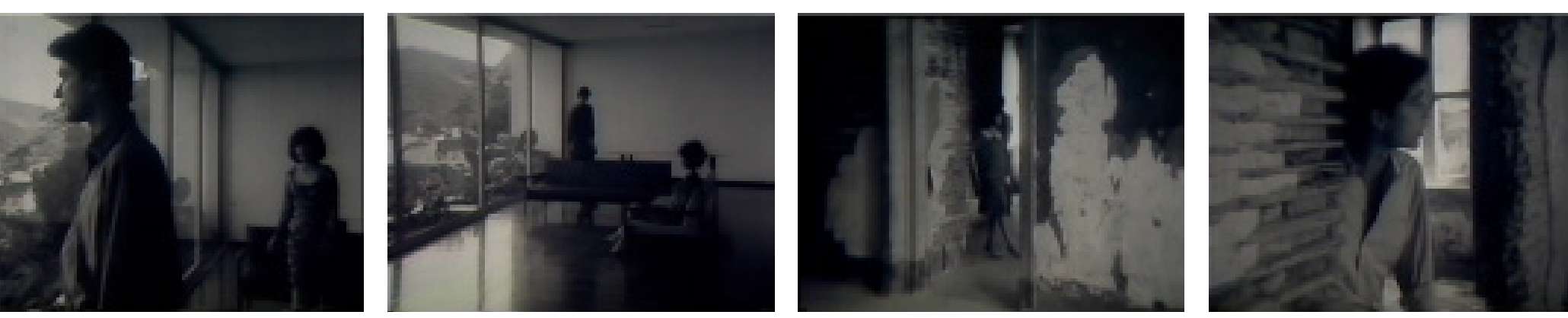

Figura 1, 2, 3 e 4, reespectivamente. 
ou porque se embebedassem

ou rotas se despregassem,

mas simplesmente porque

já estavam podres no tronco

da árvore de que as tiraram

(LIMA, 2013, p. 236)

Estão aqui as pobres coisas: cestas esfiapadas, botas carcomidas, bilhas arrebentadas, abas corroídas, com seus olhos virados para os que as deixaram sozinhas, desprezadas, esquecidas com outras coisas, sejam: búzios, conchas, madeiras de naufrágio, penas de ave e penas de caneta (LIMA, 2013, p. 237) ${ }^{6}$

Os poemas se referem ao abandono da matéria, que permanece suja, quebrada ou podre, sem uso. Dado o tom metalinguístico do filme, pode-se inferir que o olhar que Ada e Marcelo trocam, solenes, quando se lembram do título do livro, esteja vinculado ao cenário da pensão, também "apodrecendo", e ao relacionamento amoroso, que um dia pode chegar àquele estágio. Por outro lado, a cena é marcada pela ternura entre os amantes, que se acariciam e beijam.

A diegese volta para a cena no presente, mostrando ambos sentados em um sofá. Depois de outro flashback, esse mais rápido, Ada continua falando sobre a vida deles e Marcelo sobre a situação política do pós-Golpe e a necessidade de "fazer alguma coisa". Ela tenta tranquilizá-lo, pois acredita que vai conseguir "dizer alguma coisa" com o livro que pretende escrever com Carlos, mas ele retruca afirmando que uma ação individual não vai adiantar de nada. Ada afirma que de uma maneira ou de outra o artista acha um meio de criticar sua realidade. Novamente, o filme olha para si mesmo, obra de arte de um indivíduo sobre outros indivíduos, que aspira atingir o coletivo e levar à ação. Continuando a sequência, Marcelo se levanta - a câmera o enquadra em plano aberto - e vem em direção ao primeiro plano. Ele diz que acha que ninguém tem o direito de ser feliz “(...) enquanto reinar essa fome, essa miséria, essa injustiça”. Do lado esquerdo está visível o pano de vidro, mostrando "o mundo" lá fora, em frente ao qual ele se percebe paralisado.

A sequência termina com uma discussão, em que Marcelo acusa Ada e sua classe social de serem acomodadas, discorrendo sobre as injustiças sociais e a má distribuição de renda. Ada encerra a conversa, sugerindo de forma sub-reptícia o fim do relacionamento ao dizer, ironicamente: "Eu, como boa burguesa, resolvo pensar como a minha gente".

É instigante pensar na contraposição entre a casa modernista e o flashback, ambientado em uma ruína. O desgaste da relação e o impasse de Marcelo diante do Golpe, ambos alimentados por intermináveis discussóes eivadas de racionalidade — que a narrativa faz questão de expor quase sem elipses, deixando o peso de um "tempo morto" tomar conta das sequências —, é embalado pela limpeza das linhas modernistas e iluminado pelos fachos de luz que atravessam o pano de vidro da mansão. Por outro lado, a alegria que domina a cena do passado acontece em meio a um ambiente destruído, escuro, abafado. As ranhuras nas paredes enegrecidas pelas chamas servem de abrigo aos amantes, que se tocam sem receios, lendo trechos de poemas que praticamente brotam nesse solo devastado, porém rico. Embora isso não seja dito pelos personagens, é possível conjecturar que o flashback tenha acontecido antes do Golpe, quando até mesmo um ambiente caótico parecia impregnado 
de confiança e ternura. Ao contrário, no presente ambientado nas linhas retas da casa modernista, a razão vacila diante do desafio imposto pelas reviravoltas da história.

A escolha dessa oposição não parece fortuita: a simetria entre as situaçóes é tão clara, que acaba por formar uma espécie de díptico, tangenciando, e tensionando, os pares "passado" e "presente", "emoção" e "razão", "movimento" e "imobilismo". Nesta operação, enquanto a arquitetura modernista é mobilizada como elemento narrativo, acionada como signo de racionalismo, a própria capacidade de ação da arquitetura é colocada em xeque: o futuro de bonanças prometido pelas açôes racionalistas, arquitetura modernista entre eles, não veio e mandou em seu lugar um golpe de Estado. Assim como Marcelo e Ada estão estagnados, a casa, vazia, não se realizou como intervenção social ou política. Resta, inerte e impotente, como o casal de protagonistas.

\section{Notas de fim:}

1. Dib Lutfi é considerado o inventor da "câmera na mão", do slogan "Uma ideia na cabeça, uma câmera na mão", por saber conduzir o aparelho com maestria.

2. O documento do Centro de Informaçóes da Marinha, não paginado, datado de 21/09/1966, afirma: "O controle da indústria cinematográfica (...) está, atualmente, nas mãos de comunistas (...)". Entre os nomes de cineastas citados, quase todos pertencem ao Cinema Novo, incluindo Saraceni. Em seguida, sugere-se a criação de uma Censura una e nacional, visando maior eficiência no combate ao comunismo.

3. O documento não é paginado.
4. Embora o filme não forneça informações precisas a esse respeito, poderiam ser móveis assinados por Sérgio Rodrigues, Zanine Caldas, Jean Gillon, Jorge Zalszupin ou Joaquim Tenreiro.

5. As únicas músicas clássicas referenciadas nos créditos são Sonata K378, de Mozart, e Bachianas n. 5, de Villa-Lobos, mas nenhuma parece corresponder à executada nesta sequência.

6. Trata-se do Canto V, poema 6 e trecho do poema 7. No filme, só é possível ouvir os trechos, lidos por Marcelo. Optei por apresentá-los conforme a organização original proposta pelo poeta, reproduzida na ediçâo de 2013. Invenção de Orfeu ainda gozava de grande popularidade em 1965 , sendo referenciado nesta e outras obras do período (ANDRADE, 2013, p. 642).

\section{Referências Bibliográficas}

AB'SÁBER, Tales A. M. A imagem fria: cinema e crise do sujeito no Brasil dos anos 80. São Paulo: Atelier Editorial, 2003.

ANDRADE, Fábio de Souza. Posfácio: Ovo de formiga, olho do sol. In: LIMA, Jorge de. Invenção de Orfeu. São Paulo: Cosac Naify, 2013.

CAMPO, Mônica Brincalepe. O desafio: filme reflexão no pós-1964. In: CAPELATO, Maria Helena et al (orgs.). História e cinema. São Paulo: Alameda, 2011.

CAVALCANTI, Lauro. Moderno e brasileiro: a história de uma nova linguagem na arquitetura (1930-1960). Rio de Janeiro: Zahar, 2006.

CENTRO DE INFORMAÇÓES da Marinha. Fundo Polícia Política, setor Secreto, notação 11, f. 248. APERJ - Arquivo Público do Estado do Rio de Janeiro, 21/09/1966.

DELEUZE, Gilles. A imagem-tempo, Cinema II. São Paulo: Brasiliense, 2005.

GASPARI, Elio. A Ditadura envergonhada. São Paulo: Companhia das Letras, 2002. 
LIMA, Jorge de. Invenção de Orfeu. São Paulo: Cosac Naify, 2013.

ROCHA, Glauber. Revolução do Cinema Novo. São Paulo: Cosac Naify, 2004.

SGANZERLA, R. O marginal Paulo Cezar. O Estado de São Paulo, Suplemento Literário, São Paulo, 21 mai. 1966.

SILVA, J. A. P. O desafio. Cineclube Campinas, n. 2, 1966.

VIANY, Alex. O processo do Cinema Novo. Rio de Janeiro: Aeroplano, 1999.

WEINBERG, Juliana Duarte. A cidade transparente. In: NAZARIO, Luiz (org.). A cidade imaginária. São Paulo: Perspectiva, 2005. 